\title{
A COESÃO REFERENCIAL NAS CHARGES
}

MURAD, Carla Regina Rachid Otavio ${ }^{1}$ NOVAES, Diogo ${ }^{2}$

RESUMO: O objetivo deste trabalho foi observar a ocorrência dos mecanismos de coesão referencial em charges à luz dos estudos linguísticos de texto. Para tanto, foram selecionadas três charges produzidas na língua inglesa com a temática da morte de Bin Laden. Com base na noção de referenciação (MONDADA e DUBOIS, 2003) como categorização simbólica em oposição à rigidez das nomenclaturas gramaticais, foi possível constatar que o recurso de referenciação mais frequente nas charges foi a pronominalização. Com isso, a compreensão do humor se deu tipicamente do plano exofórico ou contextual, o que torna a leitura desse tipo de gênero um processo relacional que exige a ativação, pelo leitor, do seu conhecimento de mundo.

Palavras-chave: Coesão. Referência. Charge.

SUMMARY: The objective of this work is to observe the occurrence of the mechanisms of referential cohesion in political cartoons under the light of linguistic studies of texts. In this sense, three cartoons produced in English about Bin Laden's death were selected. Based on the notion of reference as a process (MONDADA e DUBOIS, 2003) of symbolic categorization in opposition to the rigidity of grammatical naming, it was possible to assure that the most frequent reference resource found in the selected political cartoons was the pronominalization. As a result, the comprehension of humor occurred tipically on the exophoric or contextual plan, which makes the reading of this type of genre a relational process that requires activation of the reader's knowledge of the world.

Keywords: Cohesion. Reference. Political Cartoon.

\section{INTRODUÇÃO}

Segundo o dicionário Aurélio, a charge é uma "representação pictórica, de caráter burlesco e caricatural, em que se satiriza um fato específico, em geral de caráter político e que é do conhecimento público". Já no Dicionário eletrônico da Língua Portuguesa, a charge é um "desenho humorístico, com ou sem legenda e balões, geralmente veiculado pela imprensa e tendo por tema algum acontecimento atual que critica, por meio de caricatura uma ou mais personagens." A partir dessas definições e do contato com esse tipo de texto na qualidade de leitora, depreendo que a charge é um texto de circulação social com características verbais e não verbais próximas da oralidade, cuja função é provocar, por meio do humor, críticas de caráter político.

A construção do humor, por sua vez, é textualmente complexa, tanto para quem produz o texto quanto para quem o lê. Ao tecer suas críticas, o produtor do texto utiliza uma série de recursos textuais para organizar as informações na linguagem, partindo da materialidade linguística para construir significados com coesão e coerência. Já o leitor, ao processar as informações, não o faz de forma literal. Koch (1997, p.28) atesta essa complexidade, ao afirmar que o leitor age na construção de sentidos de forma colaborativa, por meio de estratégias cognitivas, sociointeracionais e textuais, fazendo associações, seleções e inferências através do seu conhecimento de mundo.

Portanto, entender como funciona a coesão na criação da textualidade ou tessitura nas charges é de fundamental importância, tanto para o leitor quanto para o produtor, pois o tempo e o espaço são limitados

\footnotetext{
1 Mestre em Linguística Aplicada pela Universidade Estadual de Campinas e Doutoranda em Estudos Linguísticos na Universidade Federal de Uberlândia, Instituto de Letras e Estudos Linguísticos, Uberlândia - MG, Brasil, e-mail: carlamurad@gmail.com

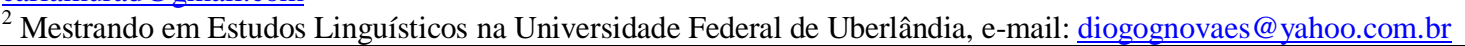


para que a comunicação se estabeleça. A tarefa de produzir e interpretar os mecanismos coesivos de referenciação nesse tipo de texto parece-me tão complexa quanto o próprio funcionamento da linguagem.

Para tanto, parto da seguinte pergunta: Como se dão os mecanismos de coesão referencial nas charges?

\section{A COESÃO TEXTUAL}

Via de regra, os referentes textuais podem ser (re)ativados por meio de duas estratégias: por anáfora, na qual o antecedente se encontra antes do elemento de retomada e por catáfora, na qual o referente se encontra na porção posterior do texto, ambas formando o que Koch denomina de "sequências veiculadoras de sentido" (p.35), por meio da conexão dos elementos linguísticos visíveis na superfície do texto, ou seja, pela coesão.

Para Marcuschi (1983 apud KOCH, p. 35), “os fatores de coesão são aqueles que dão conta da sequenciação superficial do texto, isto é, os mecanismos formais de uma língua que permitem estabelecer, entre os elementos linguísticos do texto, relações de sentido". Já Koch considera que há duas "modalidades de coesão: a remissão e a sequenciação."(p.36)

A coesão por remissão desempenha duas funções: a de ativar ou reativar referentes (remissão) ou emitir sinais (sinalização), ou seja, dar pistas para as inferências. A ativação ou reativação dos referentes se dá via referenciação anafórica ou catafórica. As remissões podem ser feitas por meio de recursos gramaticais: por pronomes pessoais do caso reto e oblíquo de terceira pessoa e os demais pronomes (possessivos, demonstrativos, indefinidos, interrogativos e relativos), por numerais e advérbios (aqui, aí, lá, ali) e artigos definidos; por elementos lexicais; sinônimos, hiperônimos, nomes genéricos e descrições definidas; por reiteração e por elipse. Em textos mais longos, quando um elemento coesivo anafórico se refere diretamente ou substitui um item especificado na sentença imediatamente anterior, tem-se um clássico padrão de "referência direta" ou "substituiçãa". Neste caso, Halliday e Hasan (1976) afirmam que haverá correferência e juntamente com ela uma tendência à formação de "cadeias coesivas" (p.15), devido ao sequenciamento provocados por esses itens no nível textual. Por conterem textos verbalmente mais breves e condensados, a presença de uma cadeia coesiva não é comum nas charges.

Já a referenciação por "pistas" se dá via inferenciação. Por exemplo, infere-se as partes pelo todo ou o todo pelas partes, por meio de conhecimentos que formam um "frame" ou "script", a partir dos elementos evidenciados na superfície do texto. Esse recurso é responsável pelo sequenciamento das informações ou fatos, garantindo-se, assim, a continuidade ou a progressão textual, por meio da utilização de termos, expressões lexicais, estruturas paralelas, paráfrases, prosódia e tempos verbais. Ainda podem se relacionar dois ou mais campos lexicais, com vistas a manter a contiguidade e a obtenção de determinados efeitos de sentido, por meio do encadeamento ou da conexão. A seguir explicitarei com mais detalhes os mecanismos de coesão referencial.

A referenciação por remissão é considerada um fenômeno de referência endofórica (HALLIDAY; HASAN, 1976), que ocorre no interior do texto ou no co-texto, por meio da anáfora e da catáfora. Em contrapartida, a remissão aos elementos externos do texto ou ao contexto é próprio de referência exofórica, realizada por meio de dêiticos, sinais ou pistas. Em outras palavras, não se teria anáfora e catáfora na exófora ou na remissão ao contexto, somente na remissão textual propriamente dita.

Nas charges, esse processo geralmente não acontece exclusivamente na materialidade linguística ou no co-texto, em que os elementos anafóricos retomam um antecedente já mencionado, pois o referente pode estar no contexto. Neste caso, diz-se que as remissões são realizadas por meio de dêiticos.

Nucleus, v.9, n.1, abr.2012 


\section{REFERÊNCIA, REFERENCIAÇÃO E CORREFERÊNCIA}

Segundo Halliday e Hasan (1976), em Linguística, um texto se refere a qualquer trecho, falado ou escrito que forma um todo em si. Não é tarefa difícil saber o que é texto, mas entrever as propriedades que o constituem e o que o distinguem de uma sequência de frases desconexas. Em suas palavras:

Um texto pode ser escrito e falado, em prosa ou verso, diálogo ou monólogo. Ele pode ser qualquer coisa, desde um único provérbio a uma peça inteira, de um momentâneo grito por socorro a uma discussão diária em um comitê. Um texto é uma unidade de língua em uso. Não é uma unidade gramatical como uma frase ou sentença e não é definido pelo seu tamanho. (HALLIDAY; HASAN, 1976, p.1)

Neste sentido, o texto é uma unidade semântica, cujo tamanho não é tão importante e sim a sua realização por meio de orações que estarão em relações semânticas.

As características linguísticas que propiciam a unidade textual são responsáveis pela garantia da textura ou tessitura. A textura, por sua vez, é proporcionada pela relação de coesão que existe entre sentenças. No exemplo de Halliday e Hasan (1976, p.2) "Lave e cozinhe seis maçãs. Coloque-as em um refratário", o pronome "as" se refere anaforicamente a "seis maçãs", proporcionando uma relação coesiva que garante a textura e, assim, a propriedade de ser um texto permanece garantida. Segundo Halliday e Hasan (1976), a relação coesiva se dá pelo fato de que "-as" e "seis maçãs" se referem à mesma coisa. Os itens são idênticos em referência. $O$ fenômeno de identidade entre referentes foi denominado de correferência. No entanto, existem casos em que essa identidade não é proporcionada pela referência direta, como, por exemplo, em: "Vou comprar um carro. -Também quero um." O carro mencionado na primeira oração pode não ser o mesmo carro mencionado na segunda. Não há uma garantia semântica de que os dois itens serão idênticos. Neste caso, ocorre o que eles denominam de co-classificação, por elipse ou substituição por pró-formas que se referem a elementos distintos, apesar da fazerem parte da mesma classe. No exemplo anterior, a classe era "carros". Há ainda outro fenômeno, denominado de co-extensão, em que a referência se dá dentro do mesmo campo semântico, por meio da hiponímia e hiperonímia.

Apesar das definições de texto, textura e coesão referencial em "Cohesion in English" de Halliday e Hasan (1976) terem sido incorporadas às teorias textuais como uma contribuição de grande valia teórica, Brown e Yule (1983) prosseguem suas investigações problematizando essas definições. Em seu texto "The nature of reference in text and in discourse", a noção de texto é expandida. Uma das primeiras observações desses autores foi que, para entender a referenciação, é necessário que os exemplos ou trechos façam sentido, ou seja, apesar do tamanho não ser o que diferencia texto de não-texto, é preciso proceder às análises de trechos mais complexos e ao exame das relações que se estabelecem na interação com o texto.

Ao questionarem as noções de substituição, referente, elipse e relação lexical do ponto de vista discursivo, Brown e Yule (1983) problematizam a identidade dos referentes ou antecedentes, mostrando que há uma transformação dos mesmos no curso da ação textual.

No caso da elipse, por exemplo, Brown e Yule questionam a noção de Halliday e Hasan (1976) de que a realização explícita das relações de sentido é requisito para que se tenha textura. Brown e Yule (1983) acreditam que são as relações semânticas de natureza implícita que realmente têm o poder coesivo. No diálogo: “A: A campainha! B: Estou no banho!" não há uma marca de coesão formal e explícita no texto que relaciona os sentidos das sentenças, mas A relação semântica pode ser percebida em virtude de nosso conhecimento de mundo.

Milner (2003) também problematiza a noção de referência partindo da análise da designação e das sequências nominais. Para se designar ou categorizar, é necessária a presença de uma sequência nominal 
que distingue um tipo específico de segmento de outro. Ao fazer essa escolha, algumas possibilidades de referência são eliminadas ao mesmo tempo em que outras são eleitas. Nessa situação ocorre o seguinte: “o segmento da realidade associado a uma sequência é sua referência real; o conjunto de condições que caracterizam uma unidade lexical é sua referência virtual" (p. 86). Em outras palavras, a virtualidade seria o eixo das possibilidades e a realidade é quando o elemento lexical está atualizado no texto. Segundo Milner (2003), "uma unidade lexical só pode ter referência real se ela for empregada; fora do emprego, ela só pode, evidentemente, comportar as condições de uma eventual referência real, quer dizer, sua referência virtual."

A intenção aqui não é fazer uma discussão teórica em torno das noções que foram problematizadas no decorrer do desenvolvimento das teorias textuais sobre a coesão referencial. $\mathrm{O}$ fato mais importante é que as problematizações acerca da referência tecidas pelos autores acima citados foram o embrião para se tratar o texto como processo discursivo e não como produto final.

É a partir de Mondade e Dubois que se começa a pensar na categorização dos objetos do discurso. Entende-se que a referência não pode estar numa relação mecânica de correspondência ou ter uma ligação direta com as coisas, com a realidade. Partindo do questionamento sobre a categorização e os processos de discretização, chega-se ao fato de que tanto as próprias categorias quanto o processo que as estabiliza são instáveis. A proposta de Mondada e Dubois é pensar na referência como um processo:

O problema não é mais, então, de se perguntar como a informação é transmitida ou como os estados do mundo são representados de modo adequado, mas de se buscar como as atividades humanas, cognitivas e linguísticas estruturam e dão sentido ao mundo. Em outros termos falaremos de referenciação, tratando-a, assim, como à categorização, como advindo de práticas simbólicas mais que de uma ontologia dada [...] uma relação entre texto e a parte não-linguística da prática em que ele é produzido e interpretado. (MONDADA; DUBOIS, 2003, p.20)

Analisando uma série de exemplos, as autoras afirmam que a referenciação é um processo construído por um processo de acerto e erro. Elas analisam textos da oralidade e prevêm que o uso de nomeações, correções, ajustes, reformas, rasuras como recursos interacionais constituem novas alternativas para o que se quer dizer. Essas descobertas também trazem implicações para o conceito de anáfora.

Apothelóz faz uma interpretação, a partir de Benveniste, na qual considera que:

As expressões anafóricas têm propriedades diferentes, e não sofrem as mesmas restrições, conforme sejam ou não controladas sintaticamente por seu antecedente (para o caso, evidentemente, de haver um). Quando tal controle existe, a interpretação do anafórico tem a inferência de uma interpretação sintática; senão, ela é dependente de fatores contextuais ou pragmáticos. (APOTHELÓZ, D.,2003, p. 53)

Com base na análise de pronomes, ele chega à conclusão que os mesmos podem ser referenciais ou não-referenciais. Se os pronomes forem ligados sintaticamente aos seus antecedentes eles não serão referenciais. Os pronomes reflexivos, por exemplo, serão "Formas Ligadas". Os pronomes pessoais, possessivos e relativos podem ter os dois funcionamentos, mas a expressão anáfora sempre designa uma forma de retomada. O antecedente passa a ser denominado de "desencadeador", pois sua função será a de desencadear a construção de sentido no texto. Em suma, tem-se a anáfora associativa ou indireta, pois a função do antecedente será a de desencadeador do discurso.

\section{ANÁLISE DAS CHARGES}

Após uma seleção de charges reunidas sob a temática da morte de Bin Laden do site 
http://politicalhumor.about.com/od/osamabinladen/ig/Osama-Bin-Laden-Cartoons/, procedo à análise das mesmas, tendo em vista os pontos arrolados na primeira parte do trabalho.

\section{Charge 1}

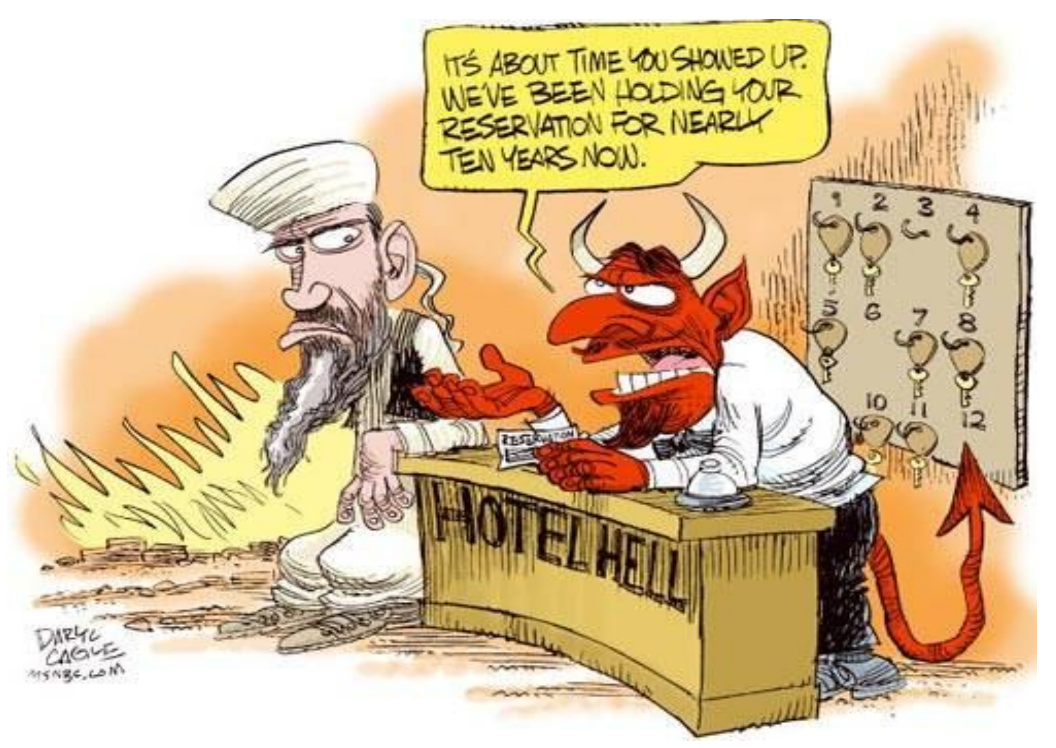

\section{“Já estava na hora de você aparecer. Estamos segurando sua reserva há quase dez anos.”}

It's about time/já estava na hora e o "now" são expressões dêiticas que estabelecem o momento da enunciação. $\mathrm{O}$ uso deste recurso é típico nas charges para que o leitor possa se situar no tempo. Nesse caso, o uso do "agora" foi um recurso enfático muito significativo, pois ressalta que a morte de Bin Laden demorou a acontecer, apesar de ter sido muito esperada e que sua falta só poderia ser sentida por "pares", que no caso são demônios.

A ironia é construída de duas formas. A primeira por meio da expressão que é geralmente usada em situações de amizade, ligando dois campos semânticos: terroristas e demônios. A segunda, que relaciona 'hotel' e 'inferno', remete a ideia de que uma reserva foi feita, mas não pelo próprio Bin Laden. Por alguém, um terceiro, que desejava sua hospedagem no Hotel Hell há quase dez anos.

O pronome endofórico ‘you' em "you showed up" encerra duas interpretações possíveis na língua inglesa, ou seja, "você", no singular, ou "vocês", no plural. No entanto, por meio do elemento não-verbal, representado pela figura de Bin Laden, associa-se à forma singular à Bin Laden, tratando-se, portanto, de um caso de referência direta por substituição ou correferenciação.

Já na segunda frase, (We've been holding your reservation for nearly ten years now/Estamos segurando sua reserva há quase dez anos) o pronome "We" ou "nós" não possui uma referência explícita nos níveis verbal ou não verbal do texto, pois não há outros diabos na figura, e sim apenas um. Assim sendo, não há a ocorrência da correferenciação. O pronome também não substitui um antecedente, constituindo seu aparecimento uma primeira ocorrência. No entanto, é possível ativar o referente "demônios" por meio de nosso conhecimento de mundo, o que torna a coesão exofórica, pois as pistas visuais nos conectam a uma informação que está fora do texto. 


\section{Charge 2}

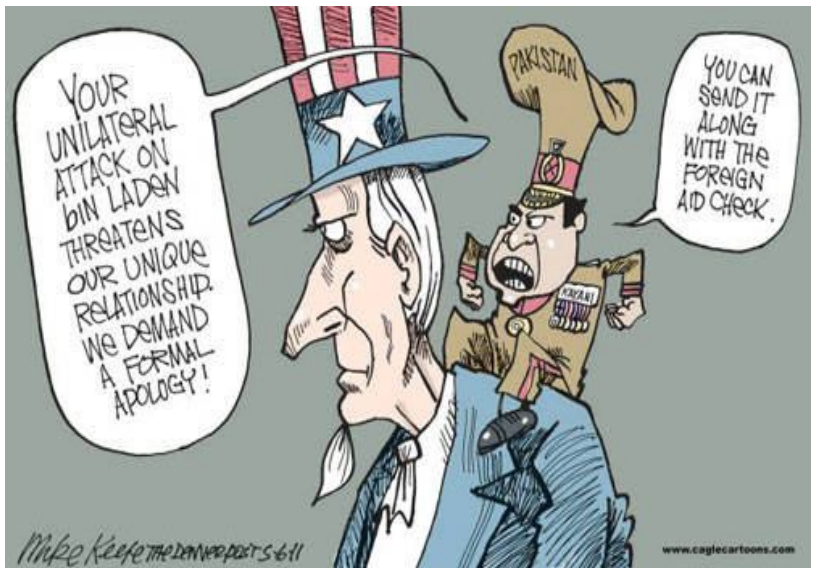

"-Seu ataque unilateral à Bin Laden ameaça nosso relacionamento único. Nós exigimos um pedido de desculpas formal.

-Você pode enviá-lo com o cheque de auxílio internacional."

O uso da pronominalização é típico da oralidade, uma característica presente nas charges. $\mathrm{O}$ excesso deles, neste caso, nos remete a uma atitude acusativa por parte do Pakistão, pretexto para tirar proveito da riqueza americana, ao aceitar um pedido de desculpas "em cheque". O humor está na ironia que o próprio Pakistão faz, ao reconhecer sua pequenez financeira com humildade forçada, o que o leva a relevar a invasão que o ataque promovido pelos Estados Unidos a Bin Laden propiciou no país.

Como os pronomes são palavras gramaticais, sem conteúdo nocional, os pronomes podem ser preenchidos, para que proporcionem a coesão referencial. No entanto, ela acontece de duas formas diferentes. O código não verbal ativa os dêiticos "your", "our" enquanto o verbal ativa "we" e "you". Nesta charge, os pronomes pessoais estão se referindo aos países: os Estados Unidos representados por um homem enorme, louro e magro, são referenciados pelos pronomes "You" e "your" e o Pakistão, representado por um homem menor sentado nos ombros dos Estados Unidos, "We" e "our".

Esses casos de pronominalização propiciam recursos de coesão exofórica, pois todos os pronomes remetem a referentes contextuais, que não são encontrados na superfície do texto, mas que podem ser relacionados com as imagens e com nosso conhecimento de mundo. À exceção do pronome 'it' que constitui uma anáfora que retoma diretamente "a formal apology", constituindo a coesão referencial por substituição.

\section{Charge 3}

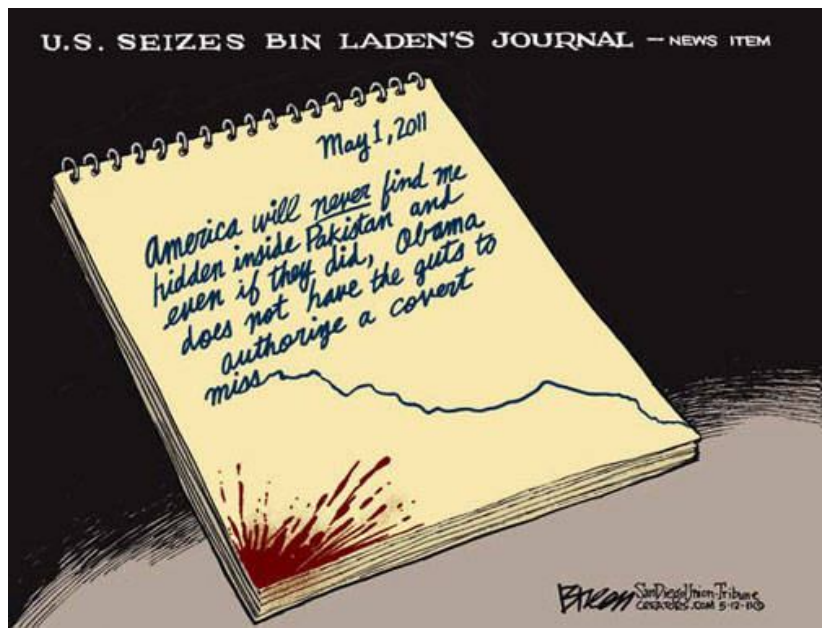




\section{Estados Unidos captura o diário de Bin Laden - item de notícia}

\section{$1^{\circ}$ de maio de 2011}

\section{A América nunca irá me encontrar escondido no Paquistão e mesmo que (eles) me encontrem, Obama não terá coragem de autorizar uma missão...}

A charge está dividida em dois planos. No primeiro, o título "Estados Unidos captura o diário de Bin Laden" e a descrição "item de notícia" remetem a situação ou contexto da enunciação, tratando-se de referência exofórica. Sua função é a de proporcionar o reconhecimento do tipo de texto que iremos encontrar no segundo plano da charge, que é um diário. Apesar de não ocorrer uma referência explícita no plano textual, a autoria do mesmo pode ser inferida pelo título.

No segundo plano, o pronome endofórico "they" não pode ser um caso de anáfora direta, pois não há um antecedente idêntico na oração o qual ele possa substituir. Trata-se de um caso de anáfora associativa, pois retoma "americanos" por associação. Assim sendo, "America" funcionou como o antecedente "desencadeador" da associação.

O humor está no fato de que a vantagem foi retomada pelos americanos em dois sentidos: pelo fato de que o ataque foi uma surpresa para Bin Laden e dele ter se constituído uma vitória para os Estados Unidos, que, até então, se considerava em dupla desvantagem: perder a batalha contra o terrorismo e não poder (ou conseguir) revidar.

\section{CONSIDERAÇÕES FINAIS}

Com base no que foi discutido anteriormente, a referência nas charges pode ser endofórica, quanto ativa um referente no interior do texto ou exofórica, quanto o referente está fora da superfície do texto ou no contexto. Endoforicamente, ela pode ser ativada ou reativada por anáfora ou catáfora. Exoforicamente, a ativação se dá por meio de dêiticos ou pistas textuais.

O recurso coesivo de referenciação mais frequente neste corpus foi a pronominalização. Porém, ela ocorreu de vários modos: endoforicamente, por meio da correferenciação, quanto houve a retomada direta por substituição e exoforicamente, por meio das pistas proporcionadas pelos dêiticos de pessoa, espaço e tempo, e ainda pelo código não verbal, que possibilitou a ativação dos referentes no contexto, por meio do conhecimento de mundo e partilhado.

A compreensão do humor se deu basicamente no plano exofórico, contextual, em que os elementos extralinguísticos propiciam a ativação do conhecimento adquirido, contribuindo para a construção das referências que são ambíguas ou oferecem duplas ou múltiplas referências, remetendo a diversos campos semânticos. A natureza dupla ou múltipla dos referentes torna a leitura deste tipo de texto um processo de referenciação colaborativo e interacional, gerando implicações de ordem interpretativa tanto para o sujeito-leitor quanto o sujeito-produtor da charge.

\section{REFERÊNCIAS}

APOTHÉLOZ, D.. "Papel e funcionamento da anáfora na dinâmica textual. In: CAVALCANTE, M. M. et al. (orgs). Referenciação. São Paulo: Contexto: 2003. p. 52-84. 
BROWN, G; YULE, G. Discourse analysis. Cambridge: Cambridge University Press. 1983. p. 153-189.

HALLIDAY, M. A. K; HASAN, R. Cohesion in English. London: Longman, 1976.

HALLIDAY, M. A. K; HASAN, R. Language, context and text: aspects of language in a social-semiotic perspective. Oxford: Oxford University Press. 1989. (Cap. 5)

KOCH, I. G. V. O texto e a construção dos sentidos. São Paulo: Contexto. 1997. p. 11-57.

MILNER, J.C. Reflexões sobre a referência e a correferência. In: CAVALCANTE, M. M. et al. (orgs.) Referenciação. São Paulo: Contexto: 2003. p. 85-130.

MONDADA, L.; DUBOIS, D. Construção dos objetos de discurso e categorização: uma abordagem dos processos referenciais. In: CAVALCANTE, M. M. et al. (orgs.) Referenciação. São Paulo: Contexto: 2003. p. 17-52. 